\title{
Technical note: A simple model to estimate changes in dietary composition of strip-grazed cattle during progressive pasture defoliations
}

\author{
A. J. Romera, ${ }^{1}$ P. Gregorini, and P. C. Beukes \\ DairyNZ, Private Bag 3221, 3240 Hamilton, New Zealand
}

\begin{abstract}
Methodological problems occur in measuring herbage intake and diet quality during short-term (4-24 h) progressive defoliations by grazing. Several models were developed to describe pasture component selection by grazing ruminants, particularly sheep. These models contain empirical coefficients to determine preferences that require laborious and data-demanding calibration. The objective was to develop a simple and practical model of changes in diet composition (green:dead) of pastures strip-grazed by dairy cows. The model was based on 3 premises when cows are strip-grazed in relatively homogeneous swards: 1) cows eat dead material only when green leaf and uncontaminated material have been removed; 2) dead material increases toward the bottom of the sward canopy; and 3) cows progressively defoliate pasture in layers. The main simplification in this model was assuming a linear decrease of green mass from the top to the bottom of the sward canopy. Thus, the proportion of green mass in the stratum eaten depended on the proportion of green in the entire sward canopy and its vertical profile. The model offers a simple solution to estimate changes in dietary compositions in pastures strip-grazed by dairy cattle during progressive pasture defoliations. It uses 2 inputs, the green mass proportion of the total herbage mass and the proportion of total herbage mass eaten during grazing. This can be optionally complemented with inputs of herbage chemical composition. The main outputs of the model are the proportions of green and dead herbage mass in the diet. For example, if the green proportion in the sward was 0.5 and the proportion of herbage mass eaten was 0.5 , then the diet would be 0.75 green:0.25 dead; assuming 0.8 and 0.4 digestibility for green and dead material, respectively, the diet digestibility would be 0.7 .
\end{abstract}

Key words: dairy cow, diet composition, strip grazing

Received October 21, 2009.

Accepted March 16, 2010.

${ }^{1}$ Corresponding author: Alvaro.Romera@dairynz.co.nz
In relatively homogeneous grazing environments such as vegetative perennial ryegrass (Lolium perenne L.)-dominated swards, an inverse relationship exists between herbage mass depletion and dietary quality (i.e., reduced digestibility and protein content and increased fiber content) of herbage consumed. Green leaf is the sward canopy component that stimulates herbage intake (Peyraud and Delaby, 2005; Gregorini et al., 2009) and quality of herbage consumed (Bailey, 1995). In a homogeneous grazing environment, strip-grazed cattle ate available herbage in successive layers when the area offered and time were restricted (Waite, 1963; Wade and Carvalho, 2000). Thus, the quality of the diet consumed depends on grazing severity, there being less green leaf and more dead material in the lower stratum (Chacon and Stobbs, 1976).

Measuring herbage intake and diet quality during short-term $(4-24 \mathrm{~h})$ progressive defoliations is time consuming, methodologically challenging, and costly; however, it is critical to obtain a good estimate of dietary intake to make pasture management decisions. Several models were developed to describe pasture component selection by grazing ruminants, particularly sheep (Pittroff and Kothmann, 2001). These models contain empirical coefficients to determine preference by animals for pasture components, which require demanding, laborious data calibration. Also, empirical coefficients usually cannot be extrapolated beyond the conditions (sward state, herbage allowance, animal type, age, and physiological state) for which they were determined. In view of this complexity but taking cognizance of the need for estimates of diet composition, a simple model, requiring few inputs and capturing the essence of the process, is preferable to a more elaborate model requiring many inputs that are impractical and costly to measure. Pregrazing herbage mass and herbage residual after grazing and green and dead proportions of the sward are likely available.

Therefore, the objective was to develop a simple and practical model of changes in dietary quality of pasture strip-grazed by dairy cows based on 3 premises when cows are strip-grazed in relatively homogeneous swards: 1) cows eat dead material only when green material and uncontaminated material have been removed; 2) 
Case a)

$\frac{\mu+b \times(1-\text { upper })+(\mu+b \times(1-\text { lower }))}{2}$

if $v=1$

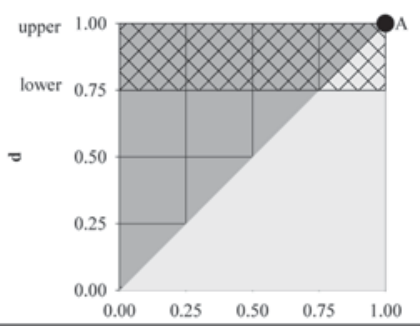

Case b)

1

if $v \leq$ lower

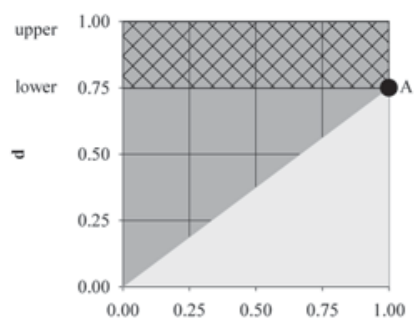

Case c)

$1-\frac{(\mu+b \times \text { upper })+(\mu+b \times \text { lower })}{2} \quad$ if $v \geq$ upper

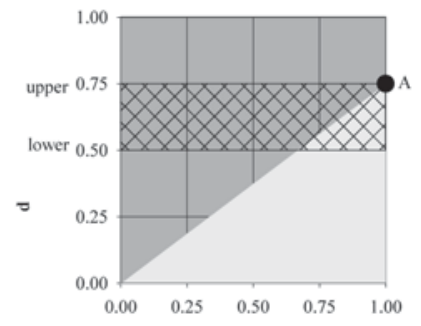

Case d)

$1-\frac{\mid v-\text { lower } \mid \times(\mu+b \times \text { lower })}{\frac{2}{\text { upper }- \text { lower }}} \quad$ lower $<v<$ upper

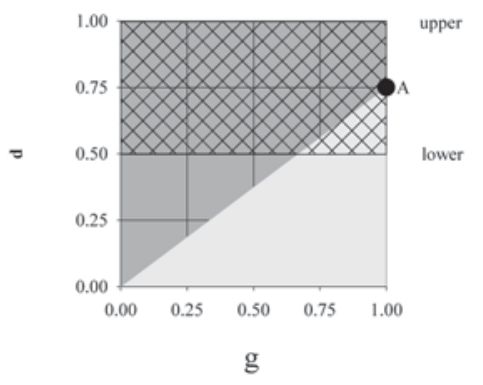

Figure 1. Schematic representation of a model of a cross-sectional cut of a sward canopy showing the vertical distribution of green (dark gray) and dead (light gray) masses and the proposed calculation of the proportion of green material for a stratum (depicted as trellis pattern) between an upper and a lower limit (greenPropUL). The vertical axis (d) represents the cumulative vertical distribution of the herbage mass (from the bottom to the top), and $g$ is the proportion of green mass at any given value of $\mathrm{d}$. The coordinates ( $\mu$ : horizontal, $\nu$ : vertical) of point $\mathrm{A}(\bullet)$ depend on the green mass proportion of the total herbage mass before grazing (greenProp; see Equations 1 and 2). Case a: greenProp is $0.5(\nu=1)$; case b: the lower limit of the stratum is at or above $\nu$; case c: the upper limit ( 0.75 in this example) is below or equal to $\nu$; case d: $v$ is between the upper and lower limits. The parameter $\mathrm{b}$ is explained in the main text.

dead material increases toward the bottom of the sward canopy; and 3) cows progressively defoliate pasture in layers from top to bottom.

The proportion of green mass in any stratum depends on the proportion of green in the entire sward canopy and its vertical profile. The main simplification in this model, based on previous research of Milne et al. (1982) and Collins (1989), was assuming a linear decrease of green mass from the top to the bottom (ground level) of the sward canopy.
The sward canopy was modeled as a series of horizontal strata, each containing a certain proportion of the total herbage mass. The proportion of green mass in a stratum between any upper and lower limits (greenPropUL) on the vertical axis was calculated as in Figure 1 (and Appendix).

Note that the vertical axis (d in Figure 1) represents the cumulative proportion of the herbage mass from ground level to top, not height. The horizontal axis (g) represents the proportion of green mass at any given 


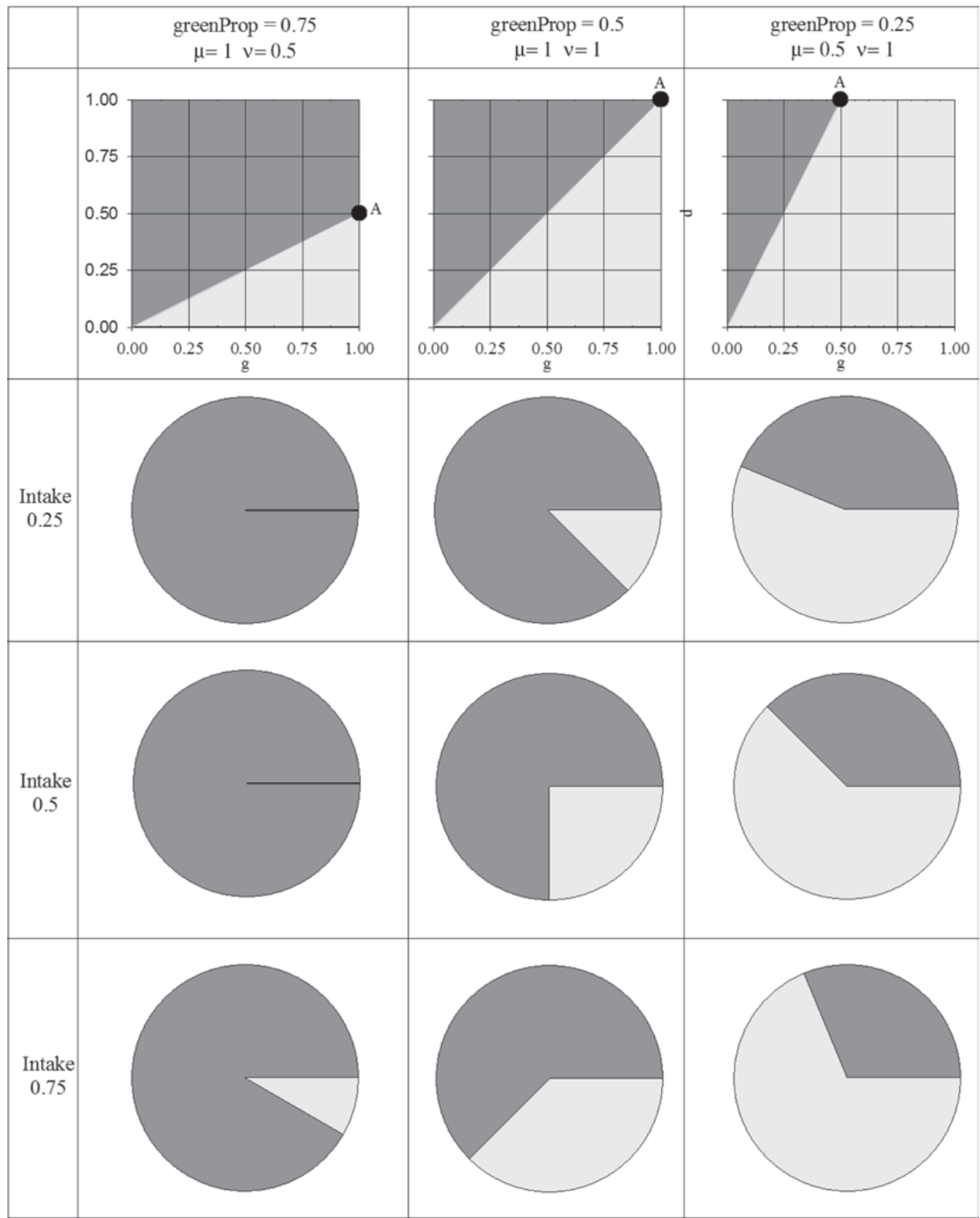

Figure 2. The area graphs (second row) show the effect of green mass proportion of the total herbage mass before grazing (greenProp) on the vertical distribution of green (dark gray) and dead (light gray) mass. The vertical axis (d) represents the cumulative vertical distribution of the herbage mass (from the bottom to the top), and $\mathrm{g}$ is the proportion of green mass at any given value of $\mathrm{d} ; \mu$ and $\nu$ are the horizontal and vertical coordinates of point A $(\bullet)$. Pie graphs show the combined effect of greenProp and proportion of the total herbage mass eaten (intake, first column) on green:dead content in the diet.

value of $\mathrm{d}$. The coordinates of the point $\mathrm{A}(\mu, \nu)$ in Figure 1 are determined as follows:

$$
\begin{gathered}
\text { if greenProp } \leq 0.5 \text {, then } \mu=2 \times \text { greenProp, } \\
\text { otherwise } \mu=1,
\end{gathered}
$$

$$
\begin{aligned}
& \text { in greenProp } \geq 0.5, \text { then } \nu=2 \times(1-\text { greenProp }) \\
& \text { otherwise } \nu=1, \\
& \text { where greenProp }=\text { green mass proportion of the total } \\
& \text { [1] herbage mass before grazing; } \mu=\text { coordinate of point }
\end{aligned}
$$


A on horizontal axis g; and $v=$ coordinates of point A on vertical axis $d$.

The parameter b in Figure 1 represents the reduction in green proportion per unit of movement down in the vertical axis $\mathrm{d}: \mathrm{b}=-\frac{\mu}{\nu}$.

Three inputs are required to determine greenPropUL: greenProp, upper limit of the stratum, and lower limit of the stratum. Case a in Figure 1 represents the special case when greenProp is 0.5 (thus, $\nu=1$ ). In the example, the green proportion in the stratum corresponding to the top 0.25 of the sward canopy mass (upper $=1$ and lower $=0.75$ ) would be 0.875 . In case $\mathrm{b}$, the lower limit of the stratum is at or above $\nu$, and all the mass in the stratum would be green (outcome is greenPropUL $=1$, for greenProp $=0.625$ in the example). In case $\mathrm{c}$, the upper limit (0.75 in this example) is below or equal to $\nu$ (outcome is greenPropUL $=0.833$, for greenProp $=$ 0.625 in the example). In case $d, \nu$ is between the upper and lower limits (outcome is greenPropUL $=0.917$, for greenProp $=0.625$ in the example). The green proportion in the diet can be calculated by substituting in Figure 1 upper with 1 and lower with the residual proportion of the total herbage mass left after grazing.

The examples in Figure 2 illustrate the model behavior. Animals eat more dead herbage mass as the proportion of total herbage mass eaten during grazing increases (pie graphs top to bottom), or the proportion of dead mass in the sward canopy increases (left to right), or both.

Once proportion of green and dead material is output from the model, then any feed fraction (e.g., CP, NDF, NSC) or digestive characteristics (e.g., DM digestibility) of herbage eaten can be calculated as a weighted average of their content on green and dead material. For example, if the green proportion in the sward was 0.5 and the proportion of herbage mass eaten was 0.5 , then the diet would be 0.75 green: 0.25 dead; assuming 0.8 and 0.4 digestibility for green and dead material, respectively, the diet digestibility would be 0.7 .

The process of herbage consumption and its measurement is complex and there is very little specific data (i.e., green and dead masses/proportion of herbage and separate intake measurements for both components, on a daily basis or during a progressive pasture defoliation) to construct or exhaustibly evaluate more complex models. Nevertheless, there is a need for predicting dietary composition in practice. Therefore, this simple approach, based on principles of pasture growth and grazing with data available, was justified. Hopefully, this is a temporary solution until data allow for more sophisticated modeling.
This model can be used to represent the plant-animal interface in models with larger spatiotemporal scales. For example, an immediate need appears in the pasturebased dairy whole farm model (WFM; Beukes et al., 2010). This WFM combined the pasture model of McCall and Bishop-Hurley (2003) for predictions of green and dead herbage mass dynamics and the cow model "Molly" (Hanigan et al., 2009) in daily time steps. A database describing pasture chemical composition (36 different traits) for each month and for green and dead components is used to feed Molly in the WFM. A more complicated model would be difficult to justify in cases like this.

In summary, the presented model offers a simple alternative to estimate changes in diet morphological composition and quality for strip-grazed cattle with varying pasture defoliation levels. The model uses 2 inputs, the green mass proportion of the total herbage mass and the proportion of total herbage mass eaten during grazing, optionally complemented with inputs of herbage chemical composition. The main outputs of the model are the proportions of green and dead herbage mass in the diet.

\section{ACKNOWLEDGMENTS}

The authors acknowledge Dave Clark and David McCall of Dairy NZ (Hamilton, New Zealand) and John McNamara (Washington State University, Pullman) for their critical review, ideas, and comments on the manuscript.

\section{REFERENCES}

Bailey, D. W. 1995. Daily selection of feeding areas by cattle in homogeneous and heterogeneous environments. Appl. Anim. Behav. Sci. 45:183-189.

Beukes, P. C., P. Gregorini, A. J. Romera, G. Levy, and G. C. Waghorn. 2010. Improving production efficiency as a strategy to mitigate greenhouse gas emissions on pastoral dairy farms in New Zealand. Agric. Ecosyst. Environ. 136:358-365.

Chacon, E. A., and T. H. Stobbs. 1976. Influence of progressive defoliation of a grass sward on the eating behaviour of cattle. Aust. J. Agric. Res. 27:709-727.

Collins, H. A. 1989. Single and mixed grazing of cattle sheep and goats. PhD Diss. Lincoln University, Canterbury, New Zealand.

Gregorini, P., S. A. Gunter, P. A. Beck, J. Caldwell, M. T. Bowman, and W. K. Coblentz. 2009. Short-term foraging dynamics of cattle grazing swards with different canopy structures. J. Anim. Sci. $87: 3817-3824$.

Hanigan, M. D., C. Palliser, and P. Gregorini. 2009. Altering the representation of hormones and pregnancy in Molly improves predictions of energy balance. J. Dairy Sci. 92:5043-5056.

McCall, D. G., and G. J. Bishop-Hurley. 2003. A pasture growth model for use in a whole-farm dairy production model. Ag. Sys. 76:1183-1205.

Milne, J. A., J. Hodgson, R. Thompson, W. G. Souter, and G. T. Barthram. 1982. The diet ingested by sheep grazing swards differing in white clover and perennial ryegrass content. Grass Forage Sci. 37:209-218. 
Peyraud, J. L., and D. L. Delaby. 2005. Combiner la gestion optimale du pasturage et les performances des vaches laitieres: Enjeux et outlis. Prod. Anim. 18:231-240.

Pittroff, W., and M. M. Kothmann. 2001. Quantitative prediction of feed intake in ruminants: I. Conceptual and mathematical analysis of models for sheep. Livest. Prod. Sci. 71:131-150.

Wade, M. H., and P. F. Carvalho. 2000. Defoliation patterns and herbage intake in grazed pastures. Pages 233-248 in Ecophysiology of Grasslands and the Ecology of Grazing. G. Lemaire, J Hodgson, A. de Moraes, P. F. Carvalho, and C. Nabinger, ed. CAB International, Oxford, UK.

Waite, R. 1963. Grazing behaviour. Pages 286-309 in Animal Health, Production and Pasture. A. N. Worden, K. C. Sellers, and D. E. Tribe, ed. Longmans, London, UK.

\section{APPENDIX}

Visual Basic code for Microsoft Excel (Microsoft Corp., Redmond, WA), where greenProp: green mass proportion of the total herbage mass before grazing,

greenPropUL: proportion of green mass in a stratum between any upper and lower limits,

$\mathrm{u}$ : coordinate of point A on horizontal axis g in Figure 1,

v: coordinates of point A on vertical axis d in Figure 1 , and

b: reduction in green proportion per unit of movement down in the vertical axis d in Figure 1.

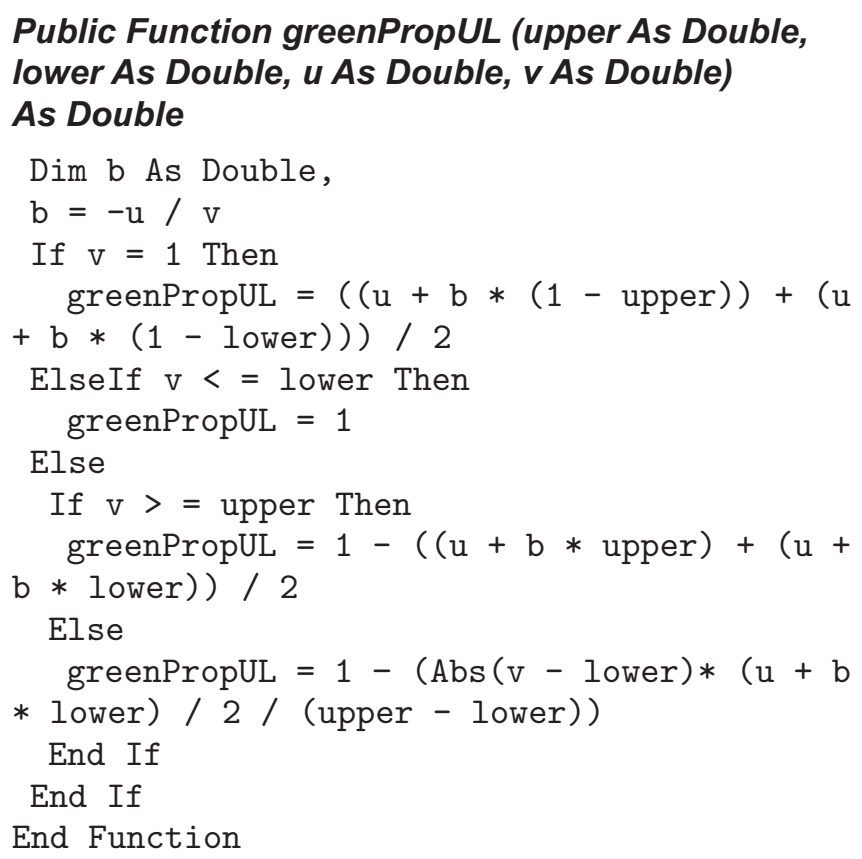

Public Function v(greenProp As Double) As Double

Dim dead As Double

dead $=1$ - greenProp

If dead $<=0.5$ Then

$\mathrm{v}=2 *$ dead

Else

$\mathrm{V}=1$

End If

End Function

Public Function u(greenProp As Double) As Double

Dim dead As Double

dead $=1-$ greenProp

If dead $>0.5$ Then

$\mathrm{u}=2 *$ greenProp

Else

$\mathrm{u}=1$

End If

End Function 